\title{
Vascular Dysfunction in Women with Recurrent Pregnancy Loss
}

\author{
Mikiya Nakastuka \\ Graduate School of Health Sciences, Okayama University \\ Department of Obstetrics and Gynecology, Okayama University Hospital
}

Japan

\section{Introduction}

Women have unique risk factors for cardiovascular diseases and cerebrovascular diseases such as pregnancy and hormone replacement therapy. Pregnancy provides an opportunity to reveal various cardiovascular disease risk factors and estimate a woman's lifetime risk because of its unique cardiovascular and metabolic stress.

The causes of recurrent pregnancy loss (RPL) are classified as genetic, anatomic, endocrinologic, immunologic, microbiologic, environmental, and further more (Kutteh, 1999; Christiansen et al., 2005). Several lines of study have suggested that certain coagulation abnormalities such as antiphospholipid antibodies or Factor V Leiden, the genetic defect underlying resistance to activated protein C, are causes of RPL (Kutteh, 1999).

New diagnostic methods have improved the clinical triage of RPL (Kutteh, 1999; Li, 1998). Transvaginal pulsed Doppler ultrasonography allows noninvasive evaluation of uterine circulation. The introduction of pulsed Doppler ultrasonography has provided noninvasive means for the evaluation of uterine impedance, and gives physiologic data, rather than anatomic information alone. It is known that resistance to uterine arterial blood flow is associated with poor obstetrical outcome such as preeclampsia and fetal growth restriction (Nakatsuka et al, 1999b; Nakatsuka et al, 2002; Takata et al, 200).

We have reported that impaired uterine perfusion is observed in a portion of women with RPL (Habara et al., 2002; Nakatsuka et al., 2003a, 2003b). Pulsed Doppler ultrasonography in the uterine artery may be useful in distinguishing women with RPL caused by vascular dysfunction from women with unexplained RPL (Habara et al., 2002). Furthermore, the plasma level of adrenomedullin, which is often associated with pathological processes of the vasculature (Hinson, 2000), is elevated in women with RPL (Nakatsuka et al., 2003a). However, vascular changes in women with RPL have not been fully elucidated.

Antiphospholipid antibody syndrome (APS), which is an autoimmune disease associated with coagulopathy, is a well-known cause of RPL (Nakatsuka et al., 2003b). Antiphospholipid antibodies refer to several groups of autoantibodies with specificity for a number of negatively-charged phospholipids such as cardiolipin, phosphatidylserine, and phosphatidylethanolamine, or phospholipid-binding glycoproteins such as $\beta 2$ glycoprotein I 
$(\beta 2 \mathrm{GPI})$ and prothrombin. There are currently data supporting an association between various types of antiphospholipid antibodies and vascular diseases (Nayak \& Komatireddy et al., 2002). Previous studies suggest that predominantly IgG and to lesser extent IgM isotype of antiphospholipid antibodies and lupus anticoagulant (LAC) are associated with arterial and venous thrombosis, thrombocytopenia, and livedo reticularis (Nayak \& Komatireddy et al., 2002). Anti-cardiolipin and anti- $\beta 2$ GPI antibodies are elevated in patients with coronary artery disease. Anti-cardiolipin antibodies are also associated with typical chest pain, significant coronary artery stenosis on angiography and prediction of myocardial infarction (Sherer \&Shoenfeld, 2003).

Premature atherosclerosis is a clinical feature of thrombotic patients with primary APS (Ames et al., 2009). Early data from the Italian Antiphospholipid Registry calculated a 2.5\% patient/year incidence of recurrent thrombosis often fatal; a prospective Spanish study demonstrated that $5.2 \%$ of primary APS patients died of recurrent arterial occlusions; Italian longitudinal study showed a $5.2 \%$ patient/year mortality rate for recurrent arterial thrombosis and a Russian group recently reported a 17\% 8-year vascular mortality for primary APS (Ames et al., 2009).

Polycystic ovary syndrome (PCOS) is one of the most common endocrinological disorders among reproductive-age women (Franks, 1995; Dunaif, 1997, The Rotterdam ESHRE/ASRM-Sponsored PCOS consensus workshop group, 2004). Using a combination of clinical, ultrasonographic, and biochemical criteria, the diagnosis of PCOS is usually reserved for those women who display one or more clinical symptoms including chronic anovulation, an ultrasonographical morphology of polycystic ovaries, inappropriate gonadotropin secretion, and hyperandrogenism (Franks, 1995; Dunaif, 1997). It is reported that women with PCOS have adverse pregnancy outcome including miscarriage (Abbott et al., 2002; Doldi et al., 1998; Glueck et al., 1999; Wang et al., 2001; Diejomaoh et al., 2003).

We and the other researchers demonstrated an impaired uterine perfusion in women with PCOS (Ajossa et al., 2002; Chekir C et al., 2005). Abnormal sex steroid hormones have been suggested as the cause for the elevated blood flow resistance in the uterine artery of women with PCOS (Zaidi et al., 1998). Furthermore, risk factors for cardiovascular disease including central obesity, hyperandrogenism, hyperinsulinemia, and dyslipidemia, which are commonly observed in women with PCOS, may lead to impairment of uterine perfusion and vascular dysfunction (Slowinska-Srzednicka et al., 1991; Legro ,2003; Sabuncu et al., 2001; Fenkci et al., 2003; Setji \& Brown, 2007).

In the light of these studies, vascular dysfunction may be the key to the pathophysiology of pregnancy loss. This chapter reviews association between RPL and vascular dysfunction.

\section{Impaired uterine arterial blood flow in women with RPL}

Pregnancy loss in LPS-treated rats is associated with coagulopathy, decreased placental blood flow, and placental and fetal hypoxia. This impairment in uteroplacental hemodynamics in LPS-treated rats is linked to increased uterine artery resistance (Graham et al., 2011). In Human, peripheral vascular resistance in normal pregnancy decreases as early as 5 weeks of gestation (Robson, 1989). Resistance in uterine arterial blood flow also exhibits a progressive decrease after implantation while it increases in women with preeclampsia or fetal growth restriction (Steel et al., 1990). Pulsed Doppler velocimetry of 
the uterine artery has been reported to predict preeclampsia, fetal growth restriction, or gestational diabetes (van den Elzen et al., 1995). However, predictive value of uterine arterial pulsed Doppler velocimetry in pregnancy loss is controversial (van den Elzen et al., 1993; Jauniaux, et al., 1994; Kurjak et al., 1994; Alcázar, 2000; Nakatsuka et al., 2003a)..

\subsection{Pregnant women with RPL associated with antiphospholipid antibodies}

We measured the resistance in the uterine arteries of 104 pregnant women with and without RPL at 4 to 5 weeks' gestation and evaluated association of autoantibodies including antiphospholipid antibodies (Nakatsuka et al., 2003a). In this study, uterine arterial pulsatility index (PI) in the RPL group was significantly higher than that in the control group (Figure 1). Women with antiphospholipid antibodies had an elevated PI in the uterine artery, which is prominent in women with RPL (Table 1). Coagulopathy and vascular dysfunction caused by antiphospholipid antibodies may impair uterine perfusion.

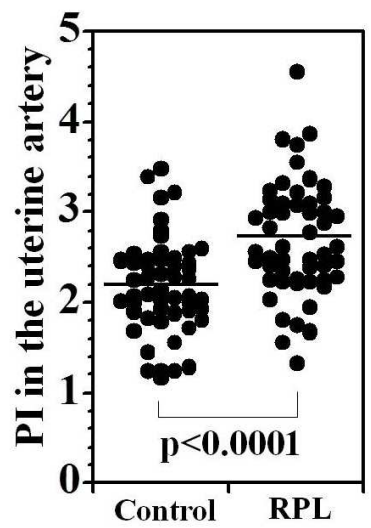

Fig. 1. Resistance in uterine arterial blood flow of women with recurrent pregnancy loss (Nakatsuka et al., 2003a).

\begin{tabular}{|c|c|c|c|}
\hline & $\begin{array}{r}\operatorname{APA}(-) \\
\quad(n=89)\end{array}$ & $\begin{array}{r}\mathbf{A P A}(+) \\
(n=15)\end{array}$ & p value \\
\hline $\begin{array}{l}\text { Control }(\mathbf{n}=52) \\
\text { Recurrent pregnancy } \\
\quad \text { loss }(\mathbf{n}=\mathbf{5 2})\end{array}$ & $\begin{array}{l}2.19 \pm 0.54 \\
(52) \\
2.51 \pm 0.52 \\
(37)\end{array}$ & $\begin{array}{c}\text { n.a. } \\
\text { (0) } \\
\text { 3.18 } \\
\text { (15) }\end{array}$ & $<0.0003$ \\
\hline Total $(n=104)$ & $2.32 \pm 0.55$ & $3.18 \pm 0.64$ & $<0.0001$ \\
\hline
\end{tabular}

APA : Antiphospholipid antibodies, n.a.: not available, Student's t-test* ${ }^{*} \mathrm{p}<0.007$.

(Nakatsuka et al., 2003a).

Table 1. Antiphospholipid antibodies and pulsatility index in the uterine artery 
Pregnancies complicated with hypertensive disorders and/or fetal growth restriction are known to be associated with a defective trophoblastic invasion. Antiphospholipid antibodies are known to interfere with syncytialization of the trophoblasts in early pregnancy and cause decidual vasculopathy, thrombosis, and placental infarction later in pregnancy. However, the elevation of uterine arterial PI that we observed is more likely to be associated with vascular dysfunction rather than impaired trophoblastic invasion. Trophoblastic invasion affects little on uterine arterial blood flow at 4-5 weeks of gestation because decrease in blood flow resistance in the uterine artery is very slow until 8 weeks of gestation (Dickey et al., 1995).

Pregnant women with antiphospholipid antibodies have vascular dysfunctions in the uterine artery although the prediction of adverse pregnancy outcome is not conclusive (Caruso et al, 1993; Venkat-Raman et al, 2001; Nakatsuka et al., 2003a).

Interestingly, the uterine arterial PI in RPL women without antiphospholipid antibodies is significantly higher than that in the control pregnant women even among women without antiphospholipid antibodies in our study (Nakatsuka et al., 2003a).

\subsection{Non-pregnant women with unexplained RPL}

Pulsed Doppler ultrasonography demonstrated blood flow changes in the uterus and ovaries during the menstrual cycle (Goswamy and Steptoe, 1988a; Chekir et al., 2005). The uterine arterial PI has been known to diminish progressively during the luteal phase, during which implantation occurs. Differences in uterine blood flow impedance between fertile and infertile women (Goswamy et al., 1988b; Steer et al., 1994). Based on studies from the IVF-ET programme, impedance of blood flow through the uterine arteries is a good indicator of the probability of subsequent pregnancy (Salle et al., 1998).

We investigated whether women with unexplained RPL have impaired uterine perfusion in the mid-luteal phase of non-conception cycles (Habara et al., 2002). The uterine arterial PI of 121 women including 49 women with unexplained RPL was measured by transvaginal pulsed Doppler ultrasonography. The uterine artery PI in RPL group $(2.54 \pm 0.45$, mean $\pm S$.D.) was significantly higher than that in the control group (2.20 \pm 0.35$)$. In the RPL group, the PI in the uterine artery of women with antinuclear antibodies (ANA) was significantly higher than that of women without ANA (Figure 2). There is no significant difference between the PI in the uterine artery of women with ANA and that of women without ANA in control group. Among women without ANA, the uterine artery PI in RPL group was also significantly higher than that in the control group.

Although ANA are not specific pathogens for pregnancy loss (Ogasawara, et al., 1996), women with positive ANA may have other autoimmune antibodies causing vasculopathy or coagulopathy. These pathological changes are likely to cause elevation of the uterine arterial blood flow resistance and lead to RPL, early onset preeclampsia, or fetal growth restriction. Although the apparent underlying pathophysiology of these cases was not elucidated, they may have subclinical vasculopathy, which was not diagnosed by routine screening tests for RPL.

\subsection{Women with PCOS}

Relatively high rate of pregnancy loss has been reported in women with PCOS. We performed a pulsed Doppler study on uterine arterial blood flow in 25 women with PCOS 
and 45 control women with regular menstrual cycles (Chekir et al.,2005). Among the control group, the uterine arterial PI in the luteal phase was significantly lower than that in the follicular phase (Figure 3). Among women with PCOS, the uterine arterial PI in the luteal phase tended to be lower than that in the follicular phase. The PI in the uterine artery in women with PCOS was significantly higher than that for the control group both in the follicular phase and in the luteal phase. Among women with PCOS, women with amenorrhea had a significantly higher uterine arterial PI than that of women with oligomenorrhea.

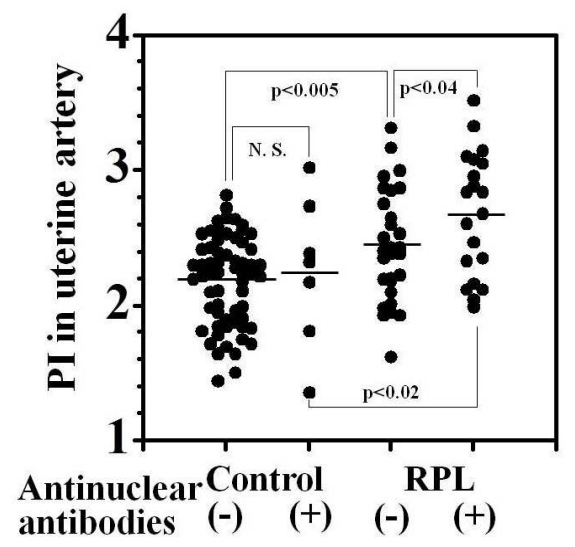

Fig. 2. Pulsatility index in the uterine artery of women with or without antinuclear antibodies in control or RPL group. Bars, Mean. Values are expressed as mean \pm S.D. (Habara et al., 2002)

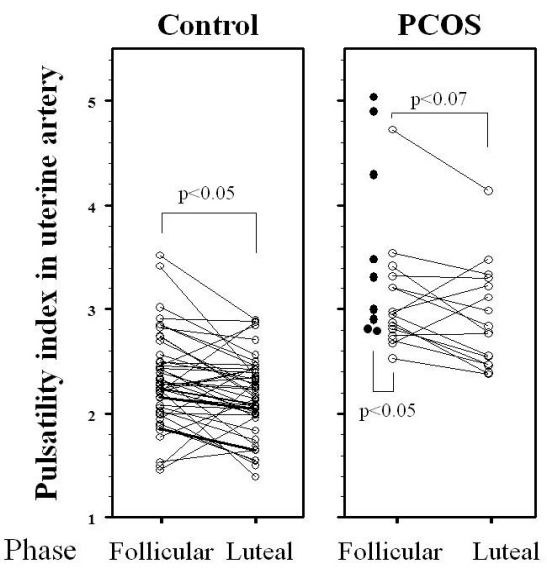

Fig. 3. Pulsatility index in the uterine artery in control women and women with PCOS. Left panel: Uterine arterial PI in control women. Data from control women during the follicular phase and the luteal phase are indicated by open circles. Right panel: Uterine arterial PI in women with PCOS. Data from women with amenorrhea during the follicular phase are indicated by closed circles. Data from women with oligomenorrhea during the follicular phase and the luteal phase are indicated by open circles (Chekir et al, 2005). 
The uterine arterial PI was correlated with body mass index, luteinizing hormone / folliclestimulating hormone ratio, or low-density lipoprotein-cholesterol (LDL-C)/high-density lipoprotein-cholesterol (HDL-C) ratio while it was inversely correlated with the HDL-C level.

\section{Biomarkers for cardiovascular risk assessment in women with RPL}

The introduction of pulsed Doppler ultrasonography has provided the means for the noninvasive evaluation of uterine impedance, thus providing physiologic data on hemodynamic abnormalities in early pregnancy failures. Are these vascular changes in women with PRL observed solely in the uterine artery? Biomarkers for cardiovascular risk assessment are substances that are released into the blood when the vasculature is damaged. Some biomarkers cause vascular dysfunction directly or indirectly. It may be worth measuring biomarkers for cardiovascular risk assessment in women with RPL.

\subsection{Thrombomodulin}

Thrombomodulin binds thrombin, changes thrombin conformation and allows thrombin to activate protein $\mathrm{C}$, which inhibits coagulation and thrombin-activatable fibrinolysis inhibitor, which inhibits fibrinolysis. Increased serum thrombomodulin, cleaved products of cellular thrombomodulin, has been demonstrated previously in preeclampsia (Dusse et al., 2011). Endothelial thrombomodulin is known to be a major vasoprotective molecule. However, elevated serum thrombomodulin is also likely to be a response to vascular activation.

We measured serum levels of soluble thrombomodulin of 54 pregnant women at 4-8 weeks of gestation (Nakatsuka et al., 2004). Serum thrombomodulin was significantly elevated in women with antiphospholipid antibodies in RPL group compared with control women and with RPL women without antiphospholipid antibodies. Among women with APS, serum thrombomodulin in women who subsequently had a growth-restricted fetus had been significantly higher than that in women who subsequently had an appropriate-for-date fetus. Elevation of thrombomodulin is likely to indicate impaired uterine blood flow in women with RPL.

It is controversial whether the soluble thrombomodulin level is an independent risk factor for coronary heart disease (Wu, 2003; Huang et al., 2008; Karakas et al., 2011). However, anti-cardiolipin antibodies are reported to be important not only in the pathogenesis of mixed connective tissue disease (MCTD) but in the induction of endothelial cell causing elevation of soluble thrombomodulin, and may play crucial roles in the development of early atherosclerosis in MCTD (Soltesz, 2010). It is also known that development of atherosclerosis and elevation of soluble thrombomodulin in serum of systemic lupus erythematosus (SLE) patients with metabolic syndrome (Mok et al., 2010).

\subsection{Adrenomedullin}

Adrenomedullin, a 52-amino acids-ringed, structured peptide, mediates vasodilatory properties through the second messenger cyclic adenosine, 3,5-monophosphate (Jougasaki \& Burnett, 2000). The main source of plasma adrenomedullin is considered to be vascular endothelial cells and vascular smooth muscle cells. 
Adrenomedullin has interaction with various bioactive molecules including nitric oxide, prostaglandins, atrial natriuretic peptide, renin, aldosterone, norepinephrine, arginine vasopressin, endothelin-1, and adrenocorticotropic hormone (Jougasaki \& Burnett, 2000). The plasma level of adrenomedullin is elevated in various diseases including hypertension, diabetes, cardiac failure, septic shock, or SLE, which are often associated with pathologic processes of the vasculature (Jougasaki \& Burnett, 2000; Hinson et al., 2000).

We measured plasma levels of adrenomedullin of 100 pregnant women in the midluteal phase of a nonpregnant cycle (Nakatsuka et al., 2003b). We also measured the PI in the uterine arteries by transvaginal pulsed Doppler ultrasonography at the same time. The plasma level of adrenomedullin in women with RPL was significantly higher than that in control women. Uterine arterial PI of women with RPL was significantly higher than that in control women. Plasma level of adrenomedullin had a significant positive correlation with uterine arterial PI both in the control group $(\mathrm{r}=0.58, \mathrm{p}<0.001)$ and in the RPL group $(\mathrm{r}=0.78$, $\mathrm{p}<0.001$ ) (Figure 4). Both plasma adrenomedullin concentration and uterine arterial PI were significantly high in women with antiphospholipid antibodies.

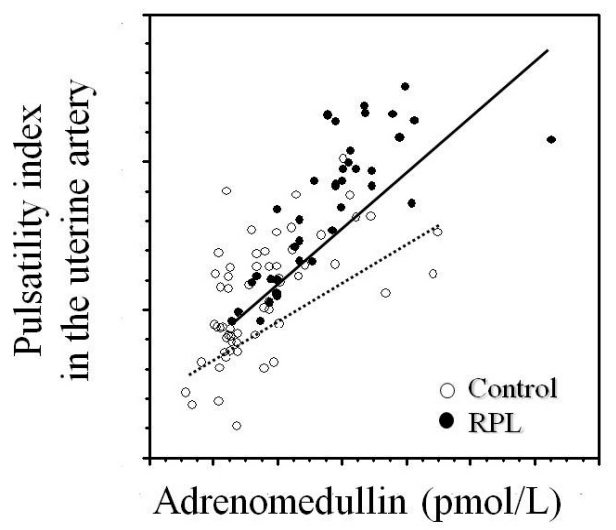

Fig. 4. Plasma adrenomedullin and uterine arterial pulsatility index.

A) Plasma adrenomedullin concentration and uterine arterial pulsatility index in control women. A significant positive correlation was determined by Pearson correlation coefficient $(\mathrm{r}=0.58, \mathrm{p}<0.001)$. B) Plasma adrenomedullin concentration and uterine arterial pulsatility index in women with recurrent pregnancy loss. A significant positive correlation was determined by Pearson correlation coefficient $(r=0.78, p<0.001)$. (Nakatsuka et al., 2003b)

Increased plasma adrenomedullin in women with RPL is likely to be a response to vascular damage and increased vascular tone. Plasma adrenomedullin levels observed in women with recurrent pregnancy loss were similar to the values reported in patients with hypertension, mitral stenosis, primary aldosteronism, or SLE (Nakatsuka et al., 2003b).

Although the pathophysiologic roles of adrenomedullin in RPL have not been fully elucidated, this peptide may serve as a biochemical marker to identify women with impaired uterine perfusion (Nakatsuka et al., 2003b; Ashraf et al., 2011) and also impaired systemic vasculatures. 


\subsection{The other markers associated with cardiovascular diseases}

We have previously reported that there is no significant difference in serum nitric oxide metabolite level between control women and women with recurrent pregnancy loss (Habara et al., 2002). However, anti-cardiolipin antibodies induce nitric oxide and superoxide production from vascular vessels, resulting in enhanced local levels of plasma peroxynitrite (Alves \& Grima, 2003), which is a powerful pro-oxidant molecule (Nakatsuka et al, 1999). These oxidative damages in the cardiovascular system may be involved in atherosclerosis.

PCOS has deserved major attention because it is linked to the same cluster of events that promote the metabolic syndrome. We have reported that women with PCOS had significantly higher total cholesterol, triglyceride, and $\beta$-lipoprotein levels than those of the control group. Significantly lower HDL-C, higher LDL-C, and consequently a higher LDL-C/HDL-C ratio were observed in women with PCOS as compared to those of the control women. Fasting serum insulin and homeostasis model assessment-R (HOMA-R), which are indexes of insulin resistance, in women with PCOS were significantly higher than those for the control group.

It has been reported that isolated adipocytes from women with PCOS express higher mRNA concentrations of some adipokines involved in cardiovascular risk and insulin resistance (Garruti et al., 2009). The actions of adipokines and adipocytokines on platelets and vascular smooth muscle cells, both of which are deeply involved in atherothrombosis, have been reported (Anfossi et al, 2010). Adipose tissue from individuals with central obesity synthesizes and releases increased amount of proinflammatory chemokines and cytokines, such as monocyte chemoattractant protein-1 (MCP-1), macrophage migration inhibitory factor (MIF), tumor necrosis factor- $\alpha$ (TNF- $\alpha$ ), and interleukins, including interleukin-1 $\beta$ (IL$1 \beta$ ) and interleukin-6 (IL-6); procoagulant and proinflammatory mediators such as tissue factor (TF) and plasminogen activator inhibitor-1 (PAI-1); vasoactive substances such as angiotensinogen and endothelin-1 (ET-1); molecules involved in the pathogenesis of insulin resistance, such as TNF-a and resistin (Anfossi et al, 2010). Elevated levels of PAI-1, the major natural antifibrinolytic agent, are involved in atherothrombosis in women with PCOS (Ehrmann, 2005). Women with RPL, who are characterized as PCOS might be monitored by measuring these bioactive molecules to predict development of cardiovascular diseases.

\section{Arterial stiffness in women with RPL}

Impaired uterine arterial blood flow and elevated cardiovascular disease risk markers suggest that early changes of systemic vasculature may be progressing in women with RPL. These changes lead to athrosclerosis and atherothrombosis and may cause coronary heart disease and/or stroke.

\subsection{Evaluation methods of arterial stiffness}

Reductions in the elasticity of central arteries may act as a marker of early changes that predispose to the development of major vascular disease. Arterial stiffness has been known as a major contributory factor to cardiovascular morbidity and mortality in patients with hypertension. Independent studies have shown that central arterial stiffness is increased in older individuals and in those with coronary artery disease, myocardial infarction, heart failure, hypertension, stroke, diabetes mellitus, end-stage renal disease, hypercholesterolemia, and inflammation (Nichols, 2005). 
There are various methods in evaluation of atherosclerosis. Intima media thickness (IMT) of carotid arteries is used to evaluate early atherosclerosis and the risk of associated cardiovascular disease (Burke, et al., 1995). The The ankle-brachial index (ABI) for each leg was calculated as the ratio of the systolic pressures in the leg and the systolic pressure of either the left or right arm. An ABI $<1.0$ in either leg was considered abnormal, suggesting peripheral arterial disease; progressively lower $\mathrm{ABI}$ values indicate more severe obstruction (Sacks et al., 2002).

Pulse wave velocity (PWV) and the augmentation index (AI) are widely used as arterial stiffness indices. Recently, brachial-ankle PWV (baPWV) measurement can be performed easily by simultaneous oscillometric measurement of pulse waves in all four extremities. Brachial-ankle PWV was used as a substitute for aortic PWV because baPWV is known to be strongly correlated with aortic PWV (Matsui et al., 2004). PWV are known to be a marker of both the severity of vascular damage and the prognosis of atherosclerotic vascular diseases in patients with hypertension (Blacher et al., 1999), end-stage renal failure (London \& Cohn, 2002), and diabetes (Yokoyama et al., 2003). Increased PWV is known to be an independent predictor of the prognosis in hypertension, including in subjects under anti-hypertensive medication (Laurent et al., 2001).

Carotid AI (cAI) was assessed by the proportion of the central pulse pressure resulting from peripheral arterial wave reflection. The AI is known to be an independent predictor of allcause and cardiovascular mortality in end-stage renal failure patients (London et al., 2001). It has been also reported that increased AI is associated with the presence and severity of coronary artery disease, particularly in younger and middle-aged male patients (Weber et al., 2004). Although PWV and AI have been known to be useful indices of atherosclerotic vascular diseases, data in young females are scarce.

\subsection{Women with PRL associated with antiphospholipid antibodies}

Antiphospholipid antibodies is known to play a central role in both pregnancy loss and cardiovascular diseases (Mackworth-Young, 2004). Antiphospholipid antibodies is a risk factor for incident stroke, however, the evidence to support the role of antiphospholipid antibodies in recurrent stroke is conflicting (Brey, 2004). Neither anti-cardiolipin antibodies nor anti- $\beta 2$ GPI antibodies is reported to be associated with atherosclerosis in premenopausal women with APS and SLE, who have an increased prevalence of carotid and femoral plaque (Vlachoyiannopoulos et al., 2003). Furthermore, previous studies have paradoxically proposed a beneficial role for some antiphospholipid antibodies in atherosclerosis (Nicolo \& Monestier, 2004).

We assessed arterial stiffness of 153 women with RPL and 66 healthy women with one or less pregnancy loss. It is reported that abnormal ABIs are more common in primary APS than in healthy controls (Baron et al., 2005). However, we did not observe significant difference in ABI value or incidence of abnormal ABI between RPL women with antiphospholipid antibodies and control women. More sensitive methods may be necessary to detect early changes of vascular system in younger patients with antiphospholipid antibodies.

Women with RPL had significantly higher baPWV than control women (Figure 5). Mean value of baPWV of RPL women with antiphospholipid antibodies is significantly higher than that in control women. None in control women or women with unexplained RPL 
showed abnormal baPWV while five in RPL women with antiphospholipid antibodies showed abnormal baPWV (baPWV > 1,400 m/sec, American Heart Association Medical/Scientific Statement, 1993). Women with RPL had significantly higher cAI (22.5 \pm $171.2 \%)$ than control women $(-67.3 \pm 151.7 \%)(\mathrm{p}<0.0005)$. Mean value of cAI of women with unexplained RPL or that of RPL women with antiphospholipid antibodies is significantly higher than that in control women (Figure 6).

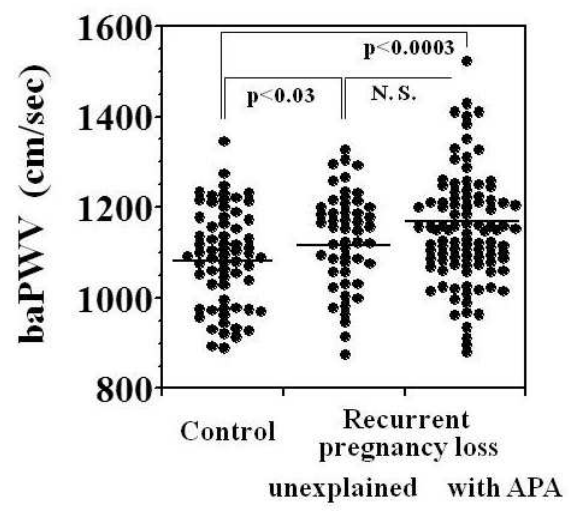

Fig. 5. baPWV of women with RPL

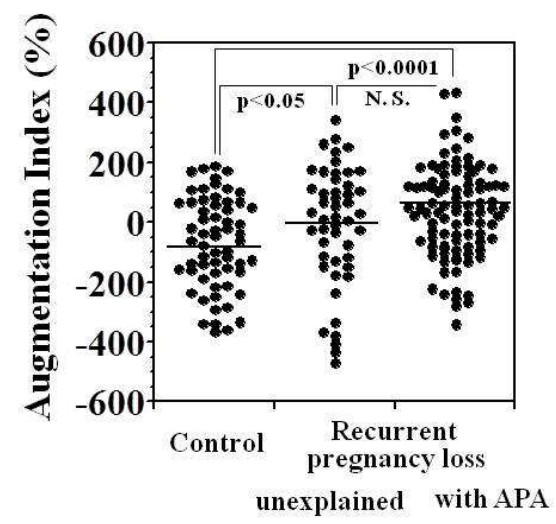

Fig. 6. cAI of women with RPL

\subsection{Types of autoimmune antibodies and arterial stiffness in women with RPL}

Antiphospholipid antibodies are a heterogeneous group of autoantibodies directed against phospholipid binding proteins, such as anti-cardiolipin antibodies, anti- $\beta 2 \mathrm{GPI}$ antibodies, and anti-phosphatidylserine/prothrombin antibodies, lupus anticoagulant, antiphosphatidylserine antibodies and anti-phosphatidylethanolamine antibodies. Pathogenesis of antiphospholipid antibodies may vary depending on types and target phospholipid. There is an increasing interest in clinical significance of various types of antiphospholipid 
antibodies to define the patient's risk of arterial and venous thrombosis (Galli et al., 2005) although it is inconclusive.

Petri have reported that twenty years after diagnosis, SLE patients with lupus anticoagulant have a $50 \%$ chance of a venous thrombotic event and myocardial infarction occurs significantly more often (22\%) in those with lupus anticoagulant (Petri, 2004). However, neither anti-cardiolipin nor lupus anticoagulant is associated with an increase of carotid IMT, carotid plaque, nor coronary calcium by helical CT, which are signs of subclinical atherosclerosis (Petri, 2004). In our study, we could not find any significant differences in baPWV or cAI between women with lupus anticoagulant and control women (Figure 7).

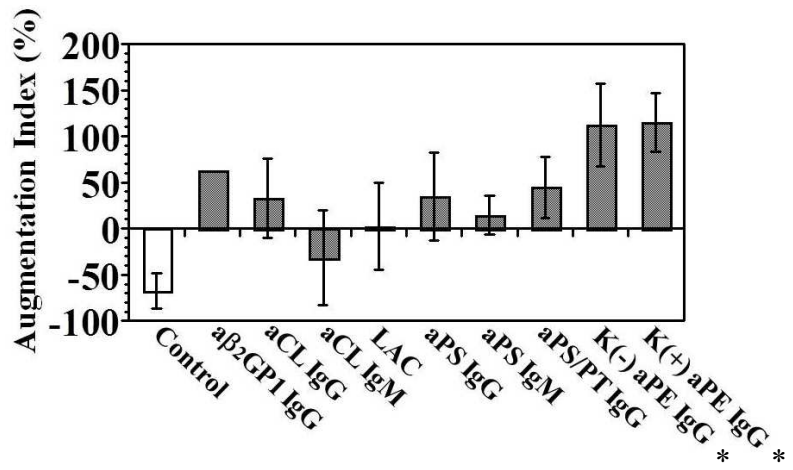

*:p< 0.05 vs. Control, a $\beta 2$ GPI: anti- $\beta 2$ GPI antibodies, aCL: anti-cardiolipin antibodies, LAC: lupus anticoagulant, aPS: anti-phosphatidylserine antibodies, aPS/PT: antibodies against phosphatidylserine/prothrombin complex, K(-)aPE: kininogen independent anti phosphatidylethanolamine antibodies, $\mathrm{K}(+) \mathrm{aPE}$ : kininogen dependent anti-phosphatidylethanolamine antibodies

Fig. 7. cAI among women with various types of APA

There is some evidence that high anti- $\beta 2$ GPI antibodies can present a risk factor for atherosclerosis, but more epidemiological data are required in order to confirm whether the pro-atherogenic properties of anti-phospholipid antibodies signifies an independent risk factor for atherosclerosis and its complications. We observed that women with anti- $\beta 2 \mathrm{GPI}$ antibodies had high cAI. Unfortunately, we could not perform statistical analysis because women with anti- $\beta 2$ GPI antibodies were small population.

It has been reported that a significantly high prevalence of anti-phosphatidylserine IgG was found in stroke patients (57.7\%) (Kahles et al., 2005). Anti-phosphatidylserine antibodies have a strong predictive value and association for arterial thrombosis (Lopez et al., 2004). Antibodies against phosphatidylserine/prothrombin complex have been reported to be closely associated with clinical features of APS rather than antibodies against prothrombin alone (Atsumi et al., 2004). However, there are no reports on atherosclerosis in women with these antibodies. We observed no significant association between anti-phosphatidylserine antibodies or antibodies against phosphatidylserine-prothrombin complex and arterial stiffness.

Recent studies have shown that some patients with unexplained thrombophilic disorders may have anti-phosphatidylethanolamine antibodies as the sole basis for their hypercoagulable 
state (Sanmarco, et al., 2001). It is noteworthy that anti-phosphatidylethanolamine antibodies have been described as the sole antiphospholipid antibodies in patients with thrombotic diseases (Staub, et al., 1989; Karmochkine, et al., 1992; Berard, et al., 1996). However, there are little studies on association of anti-phosphatidylethanolamine antibodies and arterial stiffness or atherosclerosis.

We observed that cAI was significantly increased in RPL women with antiphosphatidylethanolamine antibodies. Anti-phosphatidylethanolamine antibodies may be a risk factor for atherosclerosis in women with RPL. It has been reported that kininogendependent IgG anti-phosphatidylethanolamine antibodies markedly increases thrombininduced platelet aggregation in vitro while kininogen independent IgG antiphosphatidylethanolamine antibodies do not augment thrombin-induced platelet aggregation (Sugi et al, 1999). However, we observed that both two types of antiphosphatidylethanolamine antibodies were associated with arterial stiffness.

Physical distribution of phosphatidylethanolamine is known to be at the blood-endothelium interface. The luminal phosphatidylethanolamine is a vulnerable to antiphosphatidylethanolamine autoimmunity, which is consistent with the association between anti- phosphatidylethanolamine antibodies and elevated risk for idiopathic thrombosis (Zhixin et al., 2011).

Risk factors for atherosclerosis in SLE include traditional risk factors (mainly the Framingham risk factors). Moreover, specific antibodies to $\beta 2 \mathrm{GPI}$; anticardiolipin antibodies; anti-oxidized low-density lipoprotein (oxLDL); and antibodies to heat shock proteins may be cardiovascular disease risk factors (Sherer et al., 2010). Immune complexes containing oxLDL, $\beta 2 \mathrm{GPI}$, and/or CRP are known to be involved in atherosclerosis (Matsuura et al., 2006, Chekir et al, 2009). Autoantibodies to oxLDL/ $\beta 2$ GPI complex were detected in SLE and APS patients, and were strongly associated with arterial thrombosis (Christodoulou et al., 2007). Further studies may help evaluating clinical usefullness of these autoimmune antibodies involving in progression of atherosclerosis in women RPL.

\subsection{Women with PCOS}

Previous study on arterial stiffness has shown that both baPWV and cAI are useful for risk stratification of hypertensive patients (Matsui et al., 2004). In this study, both of these indices are significantly correlated with age and systolic blood pressure and cAI is reported to be correlated with total cholesterol and LDL-C in hypertensive patients.

We have reported that women with PCOS in reproductive age have a significantly higher baPWV than that for the control women (Sasaki et al., 2011). Arterial stiffness evaluated using the baPWV and cAI in mildly-hypertensive women (systolic blood pressure $\geq 120$ $\mathrm{mmHg}$ or diastolic blood pressure $\geq 90 \mathrm{mmHg}$ ) with PCOS was significantly higher than that in the control women or normotensive women with PCOS. Early changes in vascular function were detected in mildly-hypertensive women with PCOS.

\subsection{Women with unexplained RPL}

We observed that women with unexplained RPL showed increased baPWV and cAI in average as compared with control women (Figure 5,6). Although ranges of these indices in 
women with unexplained RPL and those in control women were overlapped, at least a portion of women with unexplained RPL showed increased baPWV and cAI. These observations suggest that antiphospholipid antibodies or endocrinological disorders may not be the sole cause for arterial stiffness in women with RPL. Vascular dysfunction caused by various factors may be involved in at least a portion of women with unexplained RPL.

A portion of women with unexplained RPL should be considered as a high risk group for atherosclerosis and cardiovascular diseases. Measurement of baPWV or AI is a promising technique to assess vascular dysfunction in women with RPL.

\section{Possible cardiovascular diseases in pregnant women with RPL}

In pregnant women with RPL, who have early changes of systemic vasculatures, may suffer vascular complications during pregnancy because of physiological hypercoagulability and hemodynamic changes associated with pregnancy.

\subsection{Venous thromboembolism (VTE)}

Thrombophilia is a risk factor for venous thromboembolism (VTE) in pregnancy because of the hypercoagulability of pregnancy, which is further increased in the presence of thrombophilia. Vascular reactivity, which is believed to be increased during pregnancy, may also compound the risk.

Pregnant women are at increased risk of venous thromboembolism (VTE). Estimated incidence of VTE during pregnancy is about 1 event per 1000 pregnancies (Chauleur et al., 2007). Despite this low incidence, thromboembolic complications occurring during pregnancy and post-partum remain a major cause of maternal death. Although pregnant women have a higher risk of developing thromboembolic complications than non-pregnant women, treating all pregnant women to prevent these events is not recommended.

A scoring system for VTE risk in pregnant women (Chauleur et al., 2007) includes antiphospholipid antibodies and reproductive history of one stillbirth or at least three recurrent miscarriages, which are clinical features of women with APS (Bobba et al., 2007).

\subsection{Coronary heart disease and stroke in pregnancy}

The risk of acute myocardial infarction is known to be approximately 3 to 4 times higher in pregnancy. The incidence of pregnancy-related acute myocardial infarction is in the broad range of 3 to 10 per 100000 deliveries that has been reported previously (James et al., 2006). Hypertension (odds ratio (OR) 21.7), thrombophilia including history of thrombosis and APS (OR 22.3), diabetes mellitus (OR 3.6), smoking (OR 8.4), transfusion (OR 5.1), postpartum infection (OR 3.2), and age 30 years and older remain as significant risk factors for pregnancy-related acute myocardial infarction in the multivariable analysis (James et al., 2006). The odds of acute myocardial infarction are 30-fold higher for women aged 40 years and older than for women 20 years of age.

Thrombophilia, gestational diabetes mellitus associated with PCOS, or age 30 years and older may increase the risk further in women with RPL. 
There are few data on the risk of stroke in relation to the full range of outcomes of pregnancy (spontaneous or induced abortion, stillbirth, and live birth) (Kittner \& Stern, 1996). One of the most important risks factors for stroke is advanced maternal age, which suggests arterial stiffness and atherosclerosis may affect on the incidence of stroke (Bushnell, 2008). The majority (48\%) of pregnancy-related strokes occur in the postpartum period, versus $41 \%$ at delivery, and 11\% antepartum (James et al., 2005). The Baltimore Washington Cooperative Young Stroke Study found that stroke rate was not increased in pregnant compared with nonpregnant women, but during the postpartum period, there was a fivefold increased risk of ischemic stroke (Kittner et al., 1996). Risk factors found to be associated with pregnancy-related stroke in the most recent analysis include thrombophilia (OR 16.0) and lupus (OR 15.2) (James et al., 2005). Preeclampsia and gestational hypertension, which are sometimes observed in women with RPL even during treatments, increase the risk of stroke during pregnancy as a result of severe hypertension and disturbed cerebral autoregulation.

\section{Reproductive history and cardiovascular disease risk later in life}

Adverse reproductive history and complications during pregnancy in women with RPL should to be considered as cardiovascular risk factors later in life. Physiological hypercoagulability, hemodynamic changes, and metabolic syndrome during pregnancy may provoke pregnancy complications including pregnancy loss, preeclampsia, placental abruption, preterm birth, or birth of an infant small for gestational age, or gestational diabetes mellitus in women with subclinical thrombophilia such as antiphospholipid antibodies or Factor V Leiden and/or subclinical endcrinological abnormalities such or PCOS. They could be considered a "failed stress test," possibly unmasking early or preexisting endothelial dysfunction and vascular or metabolic disease (Mosca, 2011).

\subsection{Parity}

Endothelial function is improved and asymmetrical dimethylarginine, an endogenous nitric oxide synthase inhibitor, decreased during pregnancy, both of which would be expected to slow the progression of atherosclerosis. In contrast, childbirth modified cardiovascular risk factors, most notably a redistribution of body fat to a phenotype characterized by increased abdominal adiposity and marked reductions in HDL-C and apoA-I.

There is an emerging body of literature examining the association between parity and cardiovascular disease. After adjustment for age, obesity, and family history of diabetes, increased parity was associated with a significantly increased risk of both non insulin dependent diabetes mellitus (NIDDM) (OR 1.16 per pregnancy) and impaired glucose tolerance (OR 1.10 per pregnancy) (Kritz-Silverstein et al., 1989).

Most of the studies on the association between parity and coronary heart disease have included only women. However, comparisons between men and women distinguish whether the mechanisms for the association between parity and atherosclerosis involve biological processes related to pregnancy or socioeconomic or lifestyle factors that are related to family size and child-rearing. It has been reported that increasing parity is associated with carotid atherosclerosis in women but not in men among a population with at least one risk factor for cardiovascular disease (Lawlor et al., 2003; Skilton et al., 2009; Skilton et al., 2010). 
Lifestyle risk factors associated with child-rearing lead to obesity and result in increased coronary heart diseass in both sexes but biological responses of pregnancy may have additional adverse effects in women (Lawlor et al., 2003).

It is suggested that the association between childbirth and concurrent changes in IMT may be independent of traditional cardiovascular risk factors (Skilton et al., 2010). However, another study described no association between parity and either IMT or presence of plaques after adjustment for age in a population based cohort of 746 Finnish women (Kharazmi et al., 2007). The causality of the link between parity and early atherosclerosis is not concluded.

\subsection{Pregnancy loss}

Women who suffered one or more pregnancy losses have had pregnancies of shorter duration than usual and consequently they have received less/shorter estrogen exposure during pregnancy. The protective effect of estrogen, therefore, is potentially less than in the case of a full-term pregnancy (Kleijn \& Schouw, 1999). However, it is more likely that cardiovascular disease risk in women with history of RPL may reflect common determinants, such as thrombophilic genetic defects, antiphospholipid antibodies, and endocrinological or metabolic disorders.

Women with subclinical cardiovascular disease could have a higher risk of pregnancy loss and cardiovascular events later in life. There have been various reports on association between pregnancy loss and coronary heart disease risk or pregnancy loss and stroke risk, which are inconclusive (de Kleijn \& Schouw, 1999; La Vecchia et al., 1987; Smith et al, 2001).

It has been reported that a history of any spontaneous loss of early pregnancy before the first live birth was associated with an increased risk of ischemic heart diseases (Smith et al., 2003). The association was independent of maternal age at the time of first birth, height, socioeconomic deprivation, essential hypertension, and complications during the first pregnancy. By contrast, there was no association between therapeutic abortion and subsequent risk of ischemic heart diseases. Women who had experienced at least one spontaneous or induced abortion had either increased or similar risk of coronary heart disease than women who had never had an abortion (Bertuccioa et al., 2007).

There is a report describing that abortions, either spontaneous or induced, are not related to myocardial infarction risk, although underreporting cannot be excluded, because some women do not realize that early abortion may have occurred and because induced abortion may not be reported (Bertuccioa et al., 2007).

\subsection{Recurrent pregnancy loss}

In women 50-74 years of age who had experienced pregnancy, history of pregnancy loss tended to be associated with a higher risk of myocardial infarction (age-adjusted OR 2.1), and the risk increased significantly with the number of pregnancy loss (age-adjusted OR 1.4) (Kharazmi et al., 2010). This result suggests that women who experience RPL are likely to be at an increased risk of vascular disease later in life. Spontaneous RPL ( $>3$ ) is associated with about five times higher risk of myocardial infarction after full adjustment (Kharazmi et al., 
2011). Women who experience spontaneous pregnancy loss are at a substantially higher risk of myocardial infarction later in life. Although women who had history of RPL (>3) tended to have a higher risk of stroke (adjusted OR 1.43), associations between RPL and cerebrovascular events including stroke are also inconclusive.

Several studies have shown associations between acquired and inherited thrombophilias and both spontaneous loss of early pregnancy and ischemic heart disease (Smith et al., 2003). High homocysteine levels in early pregnancy are another risk factor for pregnancy loss and preecclampsia (Dodds, et al., 2008). Elevated levels of homocysteine in the bloodstream can irritate the blood vessels, which may eventually lead to hardening of the arteries, stroke or heart attack.

Miscarriage can sometimes lead to infections which may also have some links with cardiovascular diseases (Kharazmi et al., 2011). For instance, chlamydia infection has been found to be associated with occurrence of miscarriage and also with atherogenesis. Inflammation and infection as known risk factors for cardiovascular diseases might be the underlying mechanisms that explain the association between miscarriage and cardiovascular disease.

It is possible that the cause of pregnancy loss is related to hemodynamic factors, such as preeclampsia, and therefore to cardiovascular risk or disease (de Kleijn \& Schouw, 1999). This means that the causal relationship could be reversed: women with a cardiovascular disease risk could have a higher risk of pregnancy loss. Occult cardiovascular, microvascular, or haemostatic dysfunction result in pregnancy complications during reproductive years and in overt cardiovascular disease later in life (Smith et al., 2003).

\subsection{Still birth}

Stillbirth is known to be associated with an increased risk of death from coronary heart disease, all circulatory and renal causes (Calderon-Margalit et al., 2007). A history of stillbirth is reported to be associated with an increased age-adjusted risk of plaque (OR 3.43), but it lost its statistical significance in the fully adjusted model (Kharazmi et al., 2007). Recent study have reported that each stillbirth increased the risk of myocardial infarction 2.32 times after adjustment for age, smoking, alcohol consumption, body mass index, waist to hip ratio, physical activity, education, number of pregnancies, hypertension, hyperlipidaemia and diabetes mellitus (Kharazmi et al., 2011). Stillbirth is a strong sexspecific predictor for myocardial infarction and thus should be considered as important indicators for cardiovascular risk factors monitoring and preventive measures (Kharazmi et al., 2011).

\section{Complications in women with RPL and cardiovascular diseases}

Pregnancy complications such as preeclampsia, placental abruption, preterm birth, or birth of an infant small for gestational age, or gestational diabetes mellitus are characteristic in women with RPL. Women with RPL are also at increased risk for recurrent episode of major depressive disorder. These complications may be associated with vascular dysfunction in women with RPL. 


\subsection{Preeclampsia}

Preeclampsia affects about $5-8 \%$ of all first pregnancies and is a major cause of maternal and fetal morbidity and mortality worldwide. Preeclampsia is associated with vascular dysfunction manifesting hypertension (Nakatsuka et al., 2002) and one of common complications observed in women with RPL even during treatment. We have reported that uterine, orbital, and brachial circulations are impaired in women with preeclampsia (Takata et al., 2002). Several studies focused on an attenuated vasodilatory response in large blood vessels by evaluating flow-mediated dilatation or venous occlusion plethysmography (Spaana et al., 2010). One study evaluated microvascular function several years after preeclampsia, observing a lower response to both endothelium-dependent and independent vasodilatation using laser Doppler imaging of the forearm 20 years after preeclampsia (Ramsay et al. 2003).

One of the most common risk factors for stroke in pregnancy, particularly postpartum, is preeclampsia/eclampsia (Bushnell \& Chireau, 2011). A history of preeclampsia during pregnancy lead to an increased risk of stroke later in life (Bellamy et al, 2007). Biomarkers of endothelial dysfunction such as intercellular adhesion molecule-1 (ICAM-1) and vascular cell adhesion molecule-1 (VCAM-1) are known to be elevated in women preeclampsia. Women with a history of preeclampsia are more likely to have higher insulin levels compared to controls.

Although the symptoms of preeclampsia typically regress within a few days post partum, impaired vascular dilatation is still present several years after preeclampsia, suggesting persistent endothelial dysfunction, which may contribute to the development of cardiovascular disease in these women (Spaana et al., 2010). A recent large meta-analysis found that women with a history of preeclampsia have approximately double the risk for subsequent ischemic heart disease, stroke, and venous thromboembolic events over the 5 to 15 years after pregnancy (Moska, 2011). Preeclampsia, particularly in association with preterm delivery, has been identified as a risk factor for myocardial infarction and mortality from cardiovascular disease later in life (James et al., 2006).

As described in the meta-analysis and other longitudinal studies, hypertension is the risk factor for cerebrovascular disease that women with a history of preeclampsia and gestational hypertension are most likely to develop (Bellamy et al, 2007).

\subsection{Anxiety and depression}

Other factors, which are prevalent among women with RPL and may make special contributions to cardiovascular disease risk, include anxiety, depression, and other psychosocial risk factors (Blackmore et al., 2011).

Anxiety, which is often observed in women with RPL, is also suggested to be an independent predictor of adverse cardiovascular events (Olafiranye et al., 2011). Individuals with high levels of anxiety are at increased risk of coronary heart disease, congestive heart failure, stroke, fatal ventricular arrhythmias, and sudden cardiac death. Anxiety following a major cardiac event can impede recovery, and is associated with a higher morbidity and mortality.

Risk for an episode of major depressive disorder among miscarrying women in the 6 months following loss is compared with the 6-month risk among community women who 
have not been pregnant in the preceding year (Neugebauer et al., 1997). Among miscarrying women, $10.9 \%$ experience an episode of major depressive disorder, compared with $4.3 \%$ of community women. The overall relative risk (RR) for an episode of major depressive disorder for miscarrying women is 2.5 and is substantially higher for childless women (RR 5.0) than for women with children (RR 1.3).

Midlife women are particularly vulnerable to depressive mood; the changing hormonal milieu during the menopausal transition contributes to increased prevalence of depressive symptoms and to the worsening of the cardiovascular disease profile (Janssen et al., 2011). Among miscarrying women with a history of major depressive disorder, $54 \%$ experience a recurrence later in life.

Symptoms of depression and major depressive disorder have been identified as potential risk factors for coronary heart disease (Janssen et al., 2011). Longitudinal studies have consistently shown that persons with high levels of depressive symptoms, or with a history of major depressive disorders, are more likely to have clinical coronary events than persons without depression. Major depression and depressive symptoms are associated with cardiovascular disease, but the impact of depression on early atherogenesis is less well known (Janssen et al., 2011). Anxiety and/or depression may be a risk factor for cardiovascular diseases in women with RPL.

\section{Vascular dysfunction in children of women with PRL}

Previous studies suggested that the atherogenic process in humans has already started during fetal development (Napoli et al, 1997). Intrauterine exposure to maternal atherosclerotic risk factors may increases the susceptibility to atherosclerosis in adult life (Alkemade et al., 2007). In a morphometric postmortem analysis of atherosclerosis in fetuses and children (Fate of Early Lesions in Children Study), it is demonstrated that specifically maternal hypercholesterolemia is associated with a higher incidence of atherosclerotic lesions during the fetal period and a faster progression of these atherosclerotic lesions after birth even under conditions of normocholesterolemia in the offspring (Napoli et al, 1999).

\subsection{Perinatal arterial ischemic stroke (PAS)}

Perinatal arterial ischemic stroke (PAS), defined as a thromboembolic event occurring before age 28 days, is an increasingly recognized cause of neurological disabilities such as cerebral palsy, epilepsy, and cognitive abnormalities (Lee et al., 2005). PAS occurs at a frequency of $1 / 1600$ to $1 / 5000$ live births (Chabriera et al., 2010). Previous fetal loss, first pregnancy, primiparity, twin-gestation, cesarean and traumatic delivery, neonatal distress, male sex and premature rupture of membranes in PAS were statistically more common than in the general population (Chabriera et al., 2010).

PAS may result from thrombosis of intracranial vessels or from embolism from another site such as extracranial vessels, heart, umbilical vein, or placenta (Nelson, 2007). Although the site of origin is usually not clearly established, it is suspected that the fetal side of the placenta may often be the source. In addition to cerebral infarction, thrombosis in other sites, including kidney, heart, aorta, and limb arteries, is more common in neonates than at other times in childhood. 
Antiphospholipid antibodies in women RPL may pass from mother to child via the placenta, can alter the placenta itself and may be a risk for PAS. The inherited thrombophilias both in mothers and fetuses may cause RPL and PAS in neonates (Nelson, 2007). It seems likely that maternal and perhaps infant thrombophilias can lead to complications of pregnancy, such as RPL, preeclampsia, placental abruption, placental vasculopathy, and fetal growth restriction, which are in turn risk factors for neonatal encephalopathy, stroke, or cerebral palsy (Nelson, 2007).

\subsection{Genetic risk factors}

Complications of pregnancy such as preeclampsia, which are observed in untreated and treated women with PRL, link to low birth weight. Previous studies have shown an association between an individual's birth weight and his or her subsequent risk of ischemic heart disease, hypertension, and diabetes mellitus (Hübinettea et al., 2001). Barker and colleagues have postulated that fetal adaptation to inadequate intrauterine nutrition, due to poor maternal diet or placental dysfunction, results in physiological programming of a "thrifty phenotype", which increases the risk of hypertension and ischemic heart disease in later life (Barker et al., 1989).

An alternative hypothesis is that common genetic factors predispose to fetal growth restriction, preterm birth, and ischemic heart diseases. Common genetic risk factors might explain the link between birthweight and risk of ischemic heart disease in both the mother and the child (Smith et al., 2001). A genetic link would be consistent with the much stronger association between birthweight and ischemic heart disease in the mother (11-fold) (Smith et al., 2001) than in the offspring (1.5-2.0-fold) (Barker et al., 1989). Maternal genes might modulate fetal growth both by affecting the intrauterine environment, for instance by effects on uterine blood flow, and by inheritance of genes from the mother that regulate fetal growth directly.

Epidemiological studies also provide evidence for common genetic links. Fathers of lowbirthweight babies are at increased risk of coronary heart disease, hypertension, and diabetes (Smith et al., 2001). Children and their mothers, who experienced RPL, may have common genetic factors linked to cardiovascular diseases.

\section{Treatment of pregnancy loss and prevention of cardiovascular diseases}

Currently, low-dose aspirin treatment is used as an effective therapy for women with RPL associated with anti-phospholipid antibodies (Coulam et al., 1997). It has been reported that low-dose aspirin is effective in improving implantation and pregnancy rates in the IVF programme (Rubinstein et al., 1999). Two trials demonstrated that women without hereditary thrombophilia and at least three unexplained consecutive losses randomized to prophylactic low molecular weight heparin had higher live birth rates than those assigned to placebo or no treatment (Bates, 2010).

Antiphospholipid antibodies are more common in patients with thrombosis but a causal association is unproven and the clinical relevance of transient or low titer antiphospholipid antibodies remains uncertain (Lim et al., 2006). In patients with APS, moderate-intensity warfarin is effective for preventing recurrent venous thrombosis and perhaps also arterial thrombosis. Aspirin appears to be as effective as moderate-intensity warfarin for preventing 
recurrent stroke in patients with prior stroke and a single positive test result for antiphospholipid antibody. Many patients with myocardial infarction and antiphospholipid antibodies are treated by warfarin.

The relationship between preeclampsia and stroke involves shared risk factors for both disorders, including chronic endothelial dysfunction and increased risk for long-term hypertension following preeclampsia, one of the major risk factors for stroke (Bushnell \& Chireau, 2010). Thrombophilic conditions and Vitamin D deficiency (Grant, 2009) has emerged as an important potentially modifiable risk factor for both preeclampsia and stroke. These overlaps provide insights into underlying pathophysiology and potential preventive strategies for both preeclampsia and stroke. For example, aspirin or Vitamin D may prevent both disorders.

Early changes in vascular function are detected in mildly-hypertensive women with PCOS (Sasaki et al., 2011). All women diagnosed with PCOS are not likely to share the same cardiovascular risk profiles and increased mortality and morbidity rates from cardiovascular disease in the PCOS population. However, lifestyle intervention such as diet and exercise should be the first-line of treatment in women with PCOS, particularly if they are hypertensive or overweight.

It is unlikely to treat all young women with aspirin following the occurrence of PRL without any other risk factors. Pharmacological therapies for hypertension, insulin resistance, or dyslipidemia are also available but should be tailored on an individual basis. It is important to evaluate arterial stiffness to identify women at early risk of cardiovascular disease and stroke and ultimately assess the risks and benefits of various prevention approaches.

\section{Conclusion}

Women who experienced RPL are at a substantially higher risk of vascular dysfunction, which leads to coronary heart disease, stroke, or VTE later in life. Reproductive history of obstetrical complications associated with RPL such as preeclampsia, premature delivery, fetal growth restriction, placental abruption, and gestational diabetes mellitus could be considered a "failed stress test," possibly unmasking early or preexisting vascular dysfunction and vascular or metabolic diseases. Therefore, these women should be carefully monitored and controlled. Healthcare professionals who meet women for the first time later in their lives should take a careful and detailed history of RPL and characteristic pregnancy complications.

Further studies will provide more information on association between PRL and vascular dysfunction, effective treatment for both women with PRL and their fetuses.

\section{References}

Abbott DH, Dumesic DA, Franks S: Developmental origin of polycystic ovary syndrome - a hypothesis. J Endocrinol 174:1-5, 2002.

Ajossa S, Guerriero S, Paoletti AM, Orru M, Melis GB: Hyperinsulinemia and uterine perfusion in patients with polycystic ovary syndrome. Ultrasound Obstet Gynecol 2:276-280, 2002. 
Alcázar JL, Ruiz-Perez ML: Uteroplacental circulation in patients with first-trimester threatened abortion. Fertil Steril 73: 130-135, 2000.

Alkemade FE, Gittenberger-de Groot AC, Schiel AE, VanMunsteren JC, Hogers B, van Vliet LS, Poelmann RE, Havekes LM, Willems van Dijk K, DeRuiter MC: Intrauterine exposure to maternal atherosclerotic risk factors increases the susceptibility to atherosclerosis in adult life. Arterioscler Thromb Vasc Biol 27: 2228-2235, 2007.

Alves JD, Grima B: Oxidative stress in systemic lupus erythematosus and antiphospholipid syndrome: a gateway to atherosclerosis. Curr Rheumatol Rep 5: 383-390, 2003.

Ames PR, Antinolfi I, Scenna G, Gaeta G, Margaglione M, Margarita A. Atherosclerosis in thrombotic primary antiphospholipid syndrome. J Thromb Haemost 7: 537-542, 2009.

Ames PR, Margarita A, Delgado Alves J, Tommasino C, Iannaccone L, Brancaccio V: Anticardiolipin antibody titre and plasma homocysteine level independently predict intima media thickness of carotid arteries in subjects with idiopathic antiphospholipid antibodies. Lupus 11:208-214, 2002.

Anfossi G, Russo I, Doronzo G, Pomero A, Trovati M: Adipocytokines in atherothrombosis: focus on platelets and vascular smooth muscle cells. Mediators Inflamm 2010:174341. Epub 2010 Jun 28.

Atsumi T, Amengual O, Yasuda S, Koike T: Antiprothrombin antibodies--are they worth assaying? Thromb Res 114: 533-538, 2004.

Barker DJ, Winter PD, Osmond C, Margetts B, Simmonds SJ: Weight in infancy and death from ischaemic heart disease. Lancet 2: 577-580, 1989.

Baron MA, Khamashta MA, Hughes GR, D'Cruz DP: Prevalence of an abnormal anklebrachial index in patients with primary antiphospholipid syndrome: preliminary data. Ann Rheum Dis 64 :144-146. 2005.

Bates SM: Consultative hematology: the pregnant patient pregnancy loss. Hematology Am Soc Hematol Educ Program 2010: 166-172, 2010.

Bellamy L, Casas JP, Hingorani AD, Williams DJ: Pre-eclampsia and risk of cardiovascular disease and cancer in later life: systematic review and meta-analysis. BMJ 335: 974. 2007.

Berard M, Chantome R, Marcelli A, Boffa MC: Antiphosphatidylethanolamine antibodies as the only antiphospholipid antibodies. I. Association with thrombosis and vascular cutaneous diseases. J Rheumatol 23: 1369-1374, 1996.

Bertuccio P, Tavani A, Gallus S, Negri E, La Vecchia C: Menstrual and reproductive factors and risk of non-fatal acute myocardial infarction in Italy. Eur J Obstet Gynecol Reprod Biol 134: 67-72, 2007.

Blacher J, Asmar R, Djane S, London GM, Safar ME. Aortic pulse wave velocity as a marker of cardiovascular risk in hypertensive patients. Hypertension 33: 1111-1117, 1999.

Blackmore ER, Côté-Arsenault D, Tang W, Glover V, Evans J, Golding J, O'Connor TG: Previous prenatal loss as a predictor of perinatal depression and anxiety. Br J Psychiatry 198: 373-378, 2011.

Bobba RS, Johnson SR, Davis AM: A review of the sapporo and revised Sapporo criteria for the classification of antiphospholipid syndrome. Where do the revised sapporo criteria add value? J Rheumatol 34: 1522-1527, 2007.

Brey RL Management of the neurological manifestations of APS--what do the trials tell us? Thromb Res 114: 489-499. 2004. 
Burke GL, Evans GW, Riley WA, Sharrett AR, Howard G, Barnes RW, Rosamond W, Crow RS, Rautaharju PM, Heiss G: Arterial wall thickness is associated with prevalent cardiovascular disease in middle-aged adults. The Atherosclerosis Risk in Communities (ARIC) Study. Stroke 26: 386-391, 1995.

Bushnell C, Chireau M: Preeclampsia and Stroke: Risks during and after Pregnancy. Stroke Res Treat. 2011 Jan 20; 2011:858134.

Bushnell CD: Stroke in women: risk and prevention throughout the lifespan. Neurol Clin 26: 1161-1176, 2008.

Calderon-Margalit R, Friedlander Y, Yanetz R, Deutsch L, Manor O, Harlap S, Paltiel O: Late stillbirths and long-term mortality of mothers. Obstet Gynecol 109: 1301-1308, 2007.

Caruso A, De Carolis S, Ferrazzani S, Valesini G, Caforio L, Mancuso S. Pregnancy outcome in relation to uterine artery flow velocity waveforms and clinical characteristics in women with antiphospholipid syndrome. Obstet Gynecol 82:970-977, 1993.

Chabrier S, Saliba E, Nguyen The Tich S, Charollais A, Varlet MN, Tardy B, Presles E, Renaud C, Allard D, Husson B, Landrieu P: Obstetrical and neonatal characteristics vary with birthweight in a cohort of 100 term newborns with symptomatic arterial ischemic stroke. Eur J Paediatr Neurol 14: 206-213, 2010.

Chauleur C, Quenet S, Varlet MN, Seffert P, Laporte S, Decousus H, Mismetti P: Feasibility of an easy-to-use risk score in the prevention of venous thromboembolism and placental vascular complications in pregnant women: a prospective cohort of 2736 women. Thromb Res 122: 478-484, 2008.

Chekir C, Nakatsuka M, Kamada Y, Noguchi S, Sasaki A, Hiramatsu Y: Impaired uterine perfusion associated with metabolic disorders in women with polycystic ovary syndrome. Acta Obstet Gynecol Scand 84: 189-195, 2005.

Chekir C, Nakatsuka M, Sasaki A, Matsuda M, Kotani S, Sharula, Shimizu K, Kamada Y, Noguchi S, Hiramatsu Y, Matsuura E: Possible vascular dysfunction in endometriosis: An increase of oxidized LDL- $\beta 2$ GPI-CRP complex in serum. Reproductive Immunology and Biology 24: 34, 2009.

Christiansen OB, Nybo Andersen AM, Bosch E, Daya S, Delves PJ, Hviid TV, Kutteh WH, Laird SM, Li TC, van der Ven K: Evidence-based investigations and treatments of recurrent pregnancy loss. Fertil Steril 83:821-839, 2005.

Christodoulou C, Sangle S, D'Cruz DP: Vasculopathy and arterial stenotic lesions in the antiphospholipid syndrome. Rheumatology (Oxford) 46: 907-910, 2007.

de Kleijn MJ, van der Schouw YT, van der Graaf Y: Reproductive history and cardiovascular disease risk in postmenopausal women: a review of the literature. Maturitas 33: 736, 1999.

de Kleijn MJ, van der Schouw YT, van der Graaf Y: Reproductive history and cardiovascular disease risk in postmenopausal women: a review of the literature. Maturitas 33:736, 1999.

Dickey RP, Hower JF: Effect of ovulation induction on uterine blood flow and oestradiol and progesterone concentrations in early pregnancy. Hum Reprod 10: 2875-2879, 1995.

Diejomaoh M, Jirous J, Al-Azemi M, Baig S, Gupta M, Tallat A: The relationship of recurrent spontaneous miscarriage with reproductive failure. Med Princ Pract 12:107-111, 2003.

Dodds L, Fell DB, Dooley KC, Armson BA, Allen AC, Nassar BA, Perkins S, Joseph KS:. Effect of homocysteine concentration in early pregnancy on gestational 
hypertensive disorders and other pregnancy outcomes. Clin Chem 54: 326-334, 2008.

Doldi N, Gessi A, Destefani A, Calzi F, Ferrari A: Polycystic ovary syndrome: anomalies in progesterone production. Hum Reprod 13:290-293, 1998.

Dunaif A: Insulin resistance and the polycystic ovary syndrome: mechanism and implications for pathogenesis. Endocr Rev 18:774-800, 1997.

Dusse L, Godoi L, Kazmi RS, Alpoim P, Petterson J, Lwaleed BA, Carvalho M: Sources of thrombomodulin in pre-eclampsia: renal dysfunction or endothelial damage? Semin Thromb Hemost 37:153-157, 2011.

Ehrmann DA: Polycystic ovary syndrome. N Engl J Med 352: 1223-1236, 2005.

El-mashad AI, Mohamed MA, Farag MA, Ahmad MK, Ismail Y: Role of uterine artery Doppler velocimetry indices and plasma adrenomedullin level in women with unexplained recurrent pregnancy loss. J Obstet Gynaecol Res 37: 51-57, 2011.

Fenkci V, Fenkci S, Yilmazer M, Serteser M. Decreased total antioxidant status and increased oxidative stress in women with polycystic ovary syndrome may contribute to the risk of cardiovascular disease. Fertil Steril 80: 123-127, 2003.

Franks S: Polycystic ovary syndrome. N Engl J Med 333:853-861, 1995.

Galli M, Barbui T: Antiphospholipid syndrome: clinical and diagnostic utility of laboratory tests. Semin Thromb Hemost 31: 17-24, 2005.

Garruti G, Depalo R, Vita MG, Lorusso F, Giampetruzzi F, Damato AB, Giorgino F: Adipose tissue, metabolic syndrome and polycystic ovary syndrome: from pathophysiology to treatment. Reprod Biomed Online 19:552-563, 2009.

Glueck CJ, Awadalla SG, Phillips H, Cameron D, Wang P, Fontaine RN: Polycystic ovary syndrome, infertility, familial thrombophilia, familial hypofibrinolysis, recurrent loss of in vitro fertilized embryos, and miscarriage. Metabolism 48: 1589-1595, 1999.

Goswamy RK, Steptoe PC: Doppler ultrasound studies of the uterine artery in spontaneous ovarian cycles. Hum. Reprod 3: 721-726, 1988a.

Goswamy RK, Williams G. Steptoe PC: Decreased uterine perfusion-a cause of infertility. Hum. Reprod 3: 955-959, 1988b.

Grant WB: Role of vitamin D in up-regulating VEGF and reducing the risk of pre-eclampsia. Clin Sci (Lond) 116: 871, 2009.

Habara T, Nakatsuka M, Konishi H, Asagiri K, Noguchi S, Kudo T: Elevated blood flow resistance in uterine arteries of women with unexplained recurrent pregnancy loss. Hum Reprod 17: 190-194, 2002.

Hinson JP, Kapas S, Smith DM: Adrenomedullin, a multifunctional regulatory peptide. Endocrine Rev 21:138-167, 2000.

Huang J, Fu G, Yao Q, Cheng G: Relation of thrombomodulin, TFPI and plasma antioxidants in healthy individuals and patients with coronary heart disease. Acta Cardiol 63:341-346, 2008.

Hübinette A, Cnattingius S, Ekbom A, de Faire U, Kramer M, Lichtenstein P: Birthweight, early environment, and genetics: a study of twins discordant for acute myocardial infarction. Lancet 357: 1997-2001, 2001.

James AH, Bushnell CD, Jamison MG, Myers ER: Incidence and risk factors for stroke in pregnancy and the puerperium. Obstet Gynecol 106:509-516, 2005. 
James AH, Jamison MG, Biswas MS, Brancazio LR, Swamy GK, Myers ER: Acute myocardial infarction in pregnancy: a United States population-based study. Circulation 113: 1564-1571, 2006.

Janssen I, Powell LH, Matthews KA, Cursio JF, Hollenberg SM, Sutton-Tyrrell K, Bromberger JT, Everson-Rose SA; SWAN study. Depressive symptoms are related to progression of coronary calcium in midlife women: the Study of Women's Health Across the Nation (SWAN) Heart Study. Am Heart J 161: 1186-1191, 2011.

Jauniaux E, Zaidi J, Jurkovic D, Campbell S, Hustin J: Comparison of colour Doppler features and pathological findings in complicated early pregnancy. Hum Reprod 9: 2432-2437, 1994.

Jougasaki M, Burnett JC Jr: Adrenomedullin: Potential in physiology and pathophysiology. Life Sci 66: 855-872, 2000.

Kahles T, Humpich M, Steinmetz H, Sitzer M, Lindhoff-Last E: Phosphatidylserine IgG and beta-2-glycoprotein I IgA antibodies may be a risk factor for ischaemic stroke. Rheumatology (Oxford) 44: 1161-1165, 2005.

Karakas M, Baumert J, Herder C, Rottbauer W, Meisinger C, Koenig W, Thorand B: Soluble thrombomodulin in coronary heart disease: lack of an association in the MONICA/KORA case-cohort study. J Thromb Haemost 9:1078-1080, 2011.

Karmochkine M, Cacoub P, Piette JC, Godear P, Boffa MC: Antiphosphatidylethanolamine antibody as the sole antiphospholipid antibody in systemic lupus erythematosus with thrombosis. Clin Exp Rheumatol 10: 603-605, 1992.

Kharazmi E, Moilanen L, Fallah M, Kaaja R, Kattainen A, Kahonen M, Jula A, Kesaniemi A, Luoto R: Reproductive history and carotid intima-media thickness. Acta Obstet Gynecol Scand 86: 995-1002, 2007.

Kharazmi E, Dossus L, Rohrmann S, Kaaks R: Pregnancy loss and risk of cardiovascular disease: A prospective population-based cohort study (EPIC-Heidelberg). Heart 97:49-54, 2011.

Kharazmi E, Fallah M, Luoto R: Miscarriage and risk of cardiovascular disease. Acta Obstet Gynecol Scand 89: 284-288, 2010.

Kittner SJ, Stern BJ, Feeser BR, Hebel R, Nagey DA, Buchholz DW, Earley CJ, Johnson CJ, Macko RF, Sloan MA, Wityk RJ, Wozniak MA: Pregnancy and the risk of stroke. N Engl J Med 335: 768-774, 1996.

Kritz-Silverstein D, Barrett-Connor E, Wingard DL: The effect of parity on the later development of non-insulin-dependent diabetes mellitus or impaired glucose tolerance. N Engl J Med 321: 1214-1219, 1989.

Kurjak A, Zalud I, Predanic M, Kupesic S: Transvaginal color and pulsed Doppler study of uterine blood flow in the first and early second trimesters of pregnancy: normal versus abnormal. J Ultrasound Med 1994; 13: 43-47.

Kutteh WH: Recurrent pregnancy loss (RPL): an update. Current Opinion Obstet Gynecol 11: 435-439, 1999.

Laurent S, Boutouyrie P, Asmar R, Gautier I, Laloux B, Guize L, Ducimetiere P, Benetos A: Aortic stiffness is an independent predictor of all-cause and cardiovascular mortality in hypertensive patients. Hypertension 37: 1236-1241, 2001 May.

La Vecchia C, Decarli A, Franceschi S, Gentile A, Negri E, Parazzini F: Menstrual and reproductive factors and the risk of myocardial infarction in women under fifty- 
five years of age. American Journal of Obstetrics \& Gynecology 157: 1108-1112, 1987.

Lawlor DA, Emberson JR, Ebrahim S, Whincup PH, Wannamethee SG, Walker M, Smith GD; British Women's Heart and Health Study; British Regional Heart Study: Is the association between parity and coronary heart disease due to biological effects of pregnancy or adverse lifestyle risk factors associated with child-rearing? Findings from the British Women's Heart and Health Study and the British Regional Heart Study. Circulation 107: 1260-1264, 2003.

Lee J, Croen LA, Lindan C, Nash KB, Yoshida CK, Ferriero DM, Barkovich AJ, Wu YW: Predictors of outcome in perinatal arterial stroke: a population-based study. Ann Neurol 58: 303-308, 2005.

Legro RS. Polycystic ovary syndrome and cardiovascular disease: a premature association? Endocr Rev 24: 302-312, 2003.

Lim W, Crowther MA, Eikelboom JW: Management of antiphospholipid antibody syndrome: a systematic review. JAMA 295: 1050-1057, 2006.

Li TC: Recurrent miscarriage: principles of management. Hum. Reprod 13: 478-482, 1998.

London GM, Blacher J, Pannier B, Guerin AP, Marchais SJ, Safar ME: Arterial wave reflections and survival in end-stage renal failure. Hypertension 38: 434-438. 2001.

London GM, Cohn JN: Prognostic application of arterial stiffness: task forces. Am J Hypertens 15: 754-758. 2002.

Lopez LR, Dier KJ, Lopez D, Merrill JT, Fink CA: Anti- $\square$ 2-glycoprotein I and antiphosphatidylserine antibodies are predictors of arterial thrombosis in patients with antiphospholipid syndrome. Am J Clin Pathol 121: 142-149, 2004.

Mackworth-Young CG: Antiphospholipid syndrome: multiple mechanisms. Clin Exp Immunol 136: 393-401, 2004.

Matsui Y, Kario K, Ishikawa J, Eguchi K, Hoshide S, Shimada K: Reproducibility of arterial stiffness indices (pulse wave velocity and augmentation index) simultaneously assessed by automated pulse wave analysis and their associated risk factors in essential hypertensive patients. Hypertens Res 27: 851-857, 2004.

Matsuura E, Kobayashi K, Tabuchi M, Lopez LR: Oxidative modification of low-density lipoprotein and immune regulation of atherosclerosis. Prog Lipid Res 45: 466-486, 2006.

Mok CC, Poon WL, Lai JP, Wong CK, Chiu SM, Wong CK, Lun SW, Ko GT, Lam CW, Lam CS: Metabolic syndrome, endothelial injury, and subclinical atherosclerosis in patients with systemic lupus erythematosus. Scand J Rheumatol 39:42-49, 2010.

Mosca L: Effectiveness-Based Guidelines for the Prevention of Cardiovascular Disease in Women-2011 Update A Guideline From the American Heart Association. Circulation 123: 1243-1262, 2011.

Nakatsuka M, Asagiri K, Kimura Y, Kamada Y, Tada K, Kudo T: Generation of peroxynitrite and apoptosis in placenta of patients with chorioamnionitis: possible implications in placental abruption. Hum. Reprod 14: 1101-1106, 1999a.

Nakatsuka M, Habara T, Noguchi S, Konishi H, Kudo T: Impaired uterine arterial blood flow in pregnant women with recurrent pregnancy loss. J Ultrasound Med 22:27-31, 2003a.

Nakatsuka M, Habara T, Noguchi S, Konishi H, Kudo T: Increased plasma adrenomedullin in women with recurrent pregnancy loss. Obstet Gynecol 102: 319-324, .2003b. 
Nakatsuka M, Noguchi S, Kamada Y, Sasaki A, Chekir C, Lin H, Hiramatsu Y: Impaired vascular function in women with recurrent pregnancy loss: Involvement of antiphospholipid antibodies. Proceedings of the IX International Congress of Reproductive Immunology - ISIR: 97-100, 2004.

Nakatsuka M, Takata M, Tada K, Asagiri K, Habara T, Noguchi S, Kudo T: A long-term transdermal nitric oxide donor improves uteroplacental circulation in women with preeclampsia. J Ultrasound Med 21: 831-836, 2002.

Nakatsuka M, Tada K, Kimura Y, Asagiri K, Kamada Y, Takata M, Nakata T, Inoue N, Kudo $\mathrm{T}$ : Clinical experience of long-term transdermal treatment with $\mathrm{NO}$ donor for women with preeclampsia. Gynecol Obstet Invest 47:13-19, 1999b.

Napoli C, D’Armiento FP, Mancini FP, Postiglione A, Witztum JL, Palumbo G, Palinski W: Fatty streak formation occurs in human fetal aortas and is greatly enhanced by maternal hypercholesterolemia. Intimal accumulation of low density lipoprotein and its oxidation precede monocyte recruitment into early atherosclerotic lesions. J Clin Invest 100:2680 -2690, 1997.

Napoli C, Glass CK, Witztum JL, Deutsch R, D'Armiento FP, Palinski W. Influence of maternal hypercholesterolaemia during pregnancy on progression of early atherosclerotic lesions in childhood: Fate of Early Lesions in Children (FELIC) study. Lancet 354: $1234-1241,1999$.

Nayak AK, Komatireddy G: Cardiac manifestations of the antiphospholipid antibody syndrome: a review. Mo Med 99:171-178, 2002.

Nelson KB: Perinatal ischemic stroke. Stroke 38: 742-745, 2007.

Neugebauer R, Kline J, Shrout P, Skodol A, O'Connor P, Geller PA, Stein Z, Susser M: Major depressive disorder in the 6 months after miscarriage. JAMA 277: 383-388, 1997.

Nichols WW: Clinical measurement of arterial stiffness obtained from noninvasive pressure waveforms. Am J Hypertens 18: 3S-10S. 2005.

Nicolo D, Monestier M: Antiphospholipid antibodies and atherosclerosis. Clin Immunol 112: 183-189, 2004.

Ogasawara M, Aoki K, Kajima S, Yagami Y: Are antinuclear antibodies predictive of recurrent miscarriage? Lancet 347: 1183-1184, 1996.

Olafiranye O, Jean-Louis G, Zizi F, Nunes J, Vincent M: Anxiety and cardiovascular risk: Review of Epidemiological and Clinical Evidence. Mind Brain 2: 32-37, 2011.

Petri M: The lupus anticoagulant is a risk factor for myocardial infarction (but not atherosclerosis): Hopkins Lupus Cohort. Thromb Res 114: 593-595, 2004.

Renaud SJ, Cotechini T, Quirt JS, Macdonald-Goodfellow SK, Othman M, Graham CH: Spontaneous pregnancy loss mediated by abnormal maternal inflammation in rats is linked to deficient uteroplacental perfusion. J Immunol 186:1799-1808, 2011.

Robson SC, Hunter S, Boys RJ, Dunlop W: Serial study of factors influencing changes in cardiac output during human pregnancy. Am J Physiol 256: H1060-H1065, 1989.

Rosendaal FR, Siscovick DS, Schwartz SM, Beverly RK, Psaty BM, Longstreth WT Jr, Raghunathan TE, Koepsell TD, Reitsma PH: Factor V Leiden (resistance to activated protein $\mathrm{C}$ ) increases the risk of myocardial infarction in young women. Blood 89: 2817-2821, 1997.

Sabuncu T, Vural H, Harma M, Harma M. Oxidative stress in polycystic ovary syndrome and its contribution to the risk of cardiovascular disease. Clin Biochem 34: 407-413, 2001. 
Sacks D, Bakal CW, Beatty PT, Becker GJ, Cardella JF, Raabe RD, Wiener HM, Lewis CA: Position statement on the use of the ankle-brachial index in the evaluation of patients with peripheral vascular disease: a consensus statement developed by the standards division of the society of cardiovascular \& interventional radiology. J Vasc Interv Radiol 13: 353, 2002.

Salle B, Bied-Damon V, Benchaib M, Desperes S, Gaucherand P, Rudigoz RC: Preliminary report of an ultrasonography and colour Doppler uterine score to predict uterine receptivity in an in-vitro fertilization programme. Hum. Reprod 13: 1669-1673, 1998.

Sanmarco M, Alessi MC, Harle JR, Sapin C, Aillaud MF, Gentile S, Juhan-Vague I, Weiller PJ: Antibodies to phosphatidylethanolamine as the only antiphospholipid antibodies found in patients with unexplained thromboses. Thromb Haemost 85: 800-805, 2001.

Sasaki A, Emi Y, Matsuda M, Sharula, Kamada Y, Chekir C, Hiramatsu Y, Nakatsuka M: Increased arterial stiffness in mildly-hypertensive women with polycystic ovary syndrome. J Obstet Gynaecol Res ;37: 402-411, 2011.

Setji TL, Brown AJ: Polycystic ovary syndrome: diagnosis and treatment. Am J Med 120: 128-32, 2007.

Sherer Y, Shoenfeld Y: Antiphospholipid antibodies: are they pro-atherogenic or an epiphenomenon of atherosclerosis? Immunobiology 207:13-16, 2003.

Sherer Y, Zinger H, Shoenfeld Y: Atherosclerosis in systemic lupus erythematosus. Autoimmunity 43: 98-102, 2010.

Skilton MR, Sérusclat A, Begg LM, Moulin P, Bonnet F: Parity and carotid atherosclerosis in men and women: insights into the roles of childbearing and child-rearing. Stroke 40: 1152-1157, 2009.

Skilton MR, Bonnet F, Begg LM, Juonala M, Kähönen M, Lehtimäki T, Viikari JS, Raitakari OT: Childbearing, child-rearing, cardiovascular risk factors, and progression of carotid intima-media thickness: the Cardiovascular Risk in Young Finns study. Stroke 41: 1332-1337, 2010.

Slowińska-Srzednicka J, Zgliczyński S, Wierzbicki M, Srzednicki M, Stopińska-Gluszak U, Zgliczyński W, Soszyński P, Chotkowska E, Bednarska M, Sadowski Z: The role of hyperinsulinemia in the development of lipid disturbances in non-obese and obese women with the polycystic ovary syndrome. J Endocrinol Invest 14: 569-575, 1991.

Smith GC, Pell JP, Walsh D: Pregnancy complications and maternal risk of ischaemic heart disease: a retrospective cohort study of 129,290 births. Lancet 357: 2002-2006, 2001.

Smith GC, Pell JP, Walsh D: Spontaneous loss of early pregnancy and risk of ischaemic heart disease in later life: retrospective cohort study. BMJ 326: 423-424, 2003.

Soltesz P, Bereczki D, Szodoray P, Magyar MT, Der H, Csipo I, Hajas A, Paragh G, Szegedi G, Bodolay E: Endothelial cell markers reflecting endothelial cell dysfunction in patients with mixed connective tissue disease. Arthritis Res Ther 12:R78, 2010.

Spaan JJ, Houben AJ, Musella A, Ekhart T, Spaanderman ME, Peeters LL: Insulin resistance relates to microvascular reactivity 23 years after preeclampsia. Microvasc Res 80: 417-421, 2010.

Staub HL, Harris EN, Khamashta MH, Savidge G, Chahade WH, Hughes GR: Antibody to phosphatidylethanolamine in a patient with lupus anticoagulant and thrombosis. Ann Rheum Dis 48: 166-169, 1989. 
Steel SA, Pearce JM, McParland P, Chamberlain GV: Early Doppler ultrasound screening in prediction of hypertensive disorders of pregnancy. Lancet 335: 1548-1551, 1990.

Steer CV, Tan AL, Mason BA, Campbell S: Midluteal-phase vaginal color Doppler assessment of uterine artery impedance in a subfertile population. Fertil. Steril 61: 53-58, 1994.

Sugi T, Katsunuma J, Izumi S, McIntyre JA, Makino T: Prevalence and heterogeneity of antiphosphatidylethanolamine antibodies in patients with recurrent early pregnancy losses. Fertil Steril 71:1060-1065, 1999.

Takata M, Nakatsuka M, Kudo T: Differential blood flow in uterine, ophthalmic, and brachial arteries of preeclamptic women. Obstet Gynecol 100: 931-939, 2002.

The Rotterdam ESHRE/ASRM-Sponsored PCOS consensus workshop group: Revised 2003 consensus on diagnostic criteria and long-term health risks related to polycystic ovary syndrome (PCOS). Hum Reprod 19:41-47, 2004.

van den Elzen HJ, Cohen-Overbeek TE, Grobbee DE, Quartero RW, Wladimiroff JW: Early uterine artery Doppler velocimetry and the outcome of pregnancy in women aged 35 years and older. Ultrasound Obstet Gynecol 5: 328-333, 1995.

van den Elzen HJ, Cohen-Overbeek TE, Grobbee DE, Wladimiroff JW. The predictive value of uterine artery flow velocity waveforms in miscarriage in older women. Br J Obstet Gynaecol 100: 762-764, 1993.

Venkat-Raman N, Backos M, Teoh TG, Lo WT, Regan L: Uterine artery Doppler in predicting pregnancy outcome in women with antiphospholipid syndrome. Obstet Gynecol 98: 235-242, 2001.

Vlachoyiannopoulos PG, Kanellopoulos PG, Ioannidis JP, Tektonidou MG, Mastorakou I, Moutsopoulos HM: Atherosclerosis in premenopausal women with antiphospholipid syndrome and systemic lupus erythematosus: a controlled study. Rheumatology (Oxford) 42: 645-651. 2003.

Weber T, Auer J, O'Rourke MF, Kvas E, Lassnig E, Berent R, Eber B: Arterial stiffness, wave reflections, and the risk of coronary artery disease. Circulation 109: 184-189, 2004.

Wang JX, Davies MJ, Norman RJ: Polycystic ovarian syndrome and the risk of spontaneous abortion following assisted reproductive technology treatment. Hum Reprod 16:2606-2609, 2001.

Wu KK: Soluble thrombomodulin and coronary heart disease. Curr Opin Lipidol 14:373-375, 2003.

Yokoyama H, Shoji T, Kimoto E, Shinohara K, Tanaka S, Koyama H, Emoto M, Nishizawa Y: Pulse wave velocity in lower-limb arteries among diabetic patients with peripheral arterial disease. J Atheroscler Thromb 10: 253-258. 2003.

Zaidi J, Jacobs H, Campbell S, Tan SL: Blood flow changes in the ovarian and uterine arteries in women with polycystic ovary syndrome who respond to clomiphene citrate: correlation with serum hormone concentrations. Ultrasound Obstet Gynecol. 12:188-196, 1998.

Zhixin Li, Wells CW, North PE, Kumar S, Duris CB, McIntyre JA, Ming Zhao: Phosphatidylethanolamine at the luminal endothelial surface--implications for hemostasis and thrombotic autoimmunity. Clin Appl Thromb Hemost 17: 158-163, 2011. 


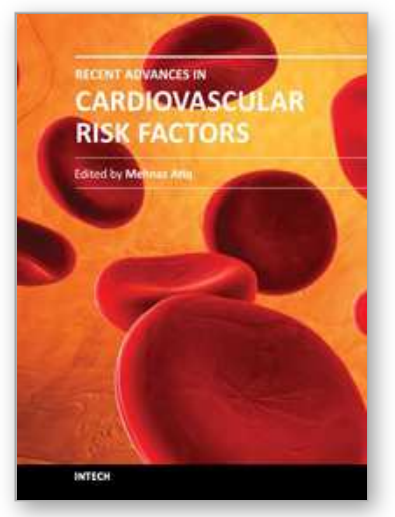

\author{
Recent Advances in Cardiovascular Risk Factors \\ Edited by Prof. Mehnaz Atiq
}

ISBN 978-953-51-0321-9

Hard cover, 522 pages

Publisher InTech

Published online 21, March, 2012

Published in print edition March, 2012

Among the non-communicable diseases, cardiovascular disorders are the leading cause of morbidity and mortality in both the developed and the developing countries. The spectrum of risk factors is wide and their understanding is imperative to prevent the first and recurrent episodes of myocardial infarction, stroke or peripheral vascular disease which may prove fatal or disabling. This book has tried to present an update on risk factors incorporating new research which has thrown more light on the existing knowledge. It has also tried to highlight regional diversity addressing such issues. It will hopefully be resourceful to the cardiologists, general practitioners, family physicians, researchers, graduate students committed to cardiovascular risk prevention.

\title{
How to reference
}

In order to correctly reference this scholarly work, feel free to copy and paste the following:

Mikiya Nakastuka (2012). Vascular Dysfunction in Women with Recurrent Pregnancy Loss, Recent Advances in Cardiovascular Risk Factors, Prof. Mehnaz Atiq (Ed.), ISBN: 978-953-51-0321-9, InTech, Available from: http://www.intechopen.com/books/recent-advances-in-cardiovascular-risk-factors/vascular-dysfunction-inwomen-with-recurrent-pregnancy-loss

\section{INTECH}

open science | open minds

\section{InTech Europe}

University Campus STeP Ri

Slavka Krautzeka 83/A

51000 Rijeka, Croatia

Phone: +385 (51) 770447

Fax: +385 (51) 686166

www.intechopen.com

\section{InTech China}

Unit 405, Office Block, Hotel Equatorial Shanghai

No.65, Yan An Road (West), Shanghai, 200040, China

中国上海市延安西路65号上海国际贵都大饭店办公楼405单元

Phone: +86-21-62489820

Fax: +86-21-62489821 
(C) 2012 The Author(s). Licensee IntechOpen. This is an open access article distributed under the terms of the Creative Commons Attribution 3.0 License, which permits unrestricted use, distribution, and reproduction in any medium, provided the original work is properly cited. 